\title{
Ultrasound assisted extraction technique: Study of the biological properties of Allium stracheyi Baker
}

\author{
- SWETA JOSHI AND MOHAMMAD ALI KHAN* \\ Department of Post Harvest Engineering and Technology, Faculty of Agricultural Sciences, Aligarh Muslim University, ALIGARH \\ (U.P.) INDIA \\ Email : sweta.sj@live.com; makamu4@yahoo.co.in

\section{SUMMARY :}

An optimized Ultrasound Assisted extraction method for the extraction of Allium stracheyi Baker extract has been developed using polar (methanol) and non-polar (n-hexane) solvent at different concentrations $(100 \%, 75 \%, 50 \%$ and $25 \%)$. The Bonferroni post hoc test revealed the presence of highest Total Phenolic Concentration (TPC), Total Flavonoid concentration (TFC) and DPPH per cent radical scavenging when using 25 per cent methanol at $50^{\circ} \mathrm{C}$ for 60 minutes. The temperature had significant effect on antioxidant activity $(\mathrm{p}<0.05)$ and non-significant effect on both TPC and TFC ( $p>0.05)$ whereas time showed significant effect for all $(p<0.05)$. The antioxidant activity had positive correlation with the TPC and TFC content. The antibacterial data illustrated inhibition zones (mm) against $E$. coli for both hexane (100\%) and methanol (100\%) solvents. No inhibition zones were found against $B$. subtilis at the same solvent concentration. Temperature and time had no significant effect on \% inhibition against the bacteria. No antibacterial activity was found against both the bacterial strains at 75 per cent, 50 per cent, 25 per cent hexane and methanol solvents. Hexane extracts showed larger inhibition zones than methanolic extracts.

KEY WORDS : Ultrasound assisted extraction, Allium stracheyi Baker, TPC, TFC, Antibacterial activity

How to cite this paper : Joshi, Sweta and Khan, Mohammad Ali (2016). Ultrasound assisted extraction technique: Study of the biological properties of Allium stracheyi Baker. Internat. J. Proc. \& Post Harvest Technol., 7 (1) : 85-95. DOI: 10.15740/HAS/IJPPHT/7.1/85-95 